Human-cat relationship in an oceanic biosphere reserve: The case of La Palma Island, Canary archipelago

\title{
Medina, FM
}

http://hdl.handle.net/10026.1/8672

\subsection{6/j.jnc.2016.04.006 \\ Journal for Nature Conservation}

All content in PEARL is protected by copyright law. Author manuscripts are made available in accordance with publisher policies. Please cite only the published version using the details provided on the item record or document. In the absence of an open licence (e.g. Creative Commons), permissions for further reuse of content should be sought from the publisher or author. 


\title{
Human-cat relationship in an oceanic biosphere reserve: The case of La Palma Island, Canary archipelago
}

\author{
Félix M. Medina ${ }^{\mathrm{a}, \mathrm{b}, *}$, Manuel Nogales ${ }^{\mathrm{b}}$, Mark J. Farnworth ${ }^{\mathrm{c}}$, Elsa Bonnaud ${ }^{\mathrm{d}}$ \\ a Servicio de Medio Ambiente, Cabildo Insular de La Palma, Avenida Los Indianos 20, $2^{\circ}, 38700$ Santa Cruz de La Palma, Canary Islands, Spain \\ ${ }^{\mathrm{b}}$ Island Ecology and Evolution Research Group (IPNA-CSIC), Astrofísico Francisco Sánchez 3, 38206 La Laguna, Tenerife, Canary Islands, Spain \\ ' School of Biological Sciences, Plymouth University, Drake Circus, Devon PL4 8AA, United Kingdom \\ ${ }^{\mathrm{d}}$ Ecologie, Systématique and Evolution, UMR CNRS 8079, Univ. Paris Sud, Orsay 91405, France
}

\section{A R T I C L E I N F O}

\section{Article history:}

Received 8 April 2015

Received in revised form 21 April 2016

Accepted 22 April 2016

\section{Keywords:}

Conservation

Felis catus

Invasive species

Oceanic islands

Questionnaires

Human-animal relationship

\begin{abstract}
A B S T R A C T
Removal of feral cats from island environments is a useful mechanism by which their ecological impact on endangered species can be reduced or ended. Nevertheless, because cats are anthropogenic in their origins, social perceptions of management practices play a large role in their implementation. Fourhundred questionnaires were delivered ( 386 were returned) with 100 going to each of the following: local residents; environmental workers; tourists; and, hunters. Questions explored respondents' knowledge about island biodiversity and invasive species as well as attitudes towards cat population management methods. Habitat destruction and introduction of invasive species were considered the main threats for the conservation of island biodiversity. Most respondents considered cats to have a negative impact on biodiversity and sterilization campaigns were considered most appropriate for cat population control. Several free sterilization campaigns have been conducted in La Palma Island Biosphere Reserve in order to reduce free-ranging cats and were well received by local people. This research, which combined concepts of management, ecology and social sciences, provides valuable insights which may to be applicable on several other islands where cats and people are present and in conflict with conservation priorities.
\end{abstract}

(c) 2016 Elsevier GmbH. All rights reserved.

\section{Introduction}

The domestic cat (Felis silvestris catus) originates from the Near Eastern wildcats (F. s. lybica) approximately 9000 years ago (Driscoll et al., 2007). This commensal relationship likely arose from the cat's ability to effectively control rodents but has, over time, developed into one of companionship (Turner, 2000). Three different statuses for cats have been broadly described depending on their associations with humans: (1) house/pet/companion cats living with people that provide food, affection and shelter; (2) stray or roaming cats linked to one or several households which receive some of their nutritional needs from people but may be required to hunt; and, (3) feral cats independent of humans that reproduce and feed independently of people and anthropogenic food sources (see Farnworth, Dye, \& Keown, 2010; Liberg, Sandell, Pontier, \& Natoli, 2000).

\footnotetext{
* Corresponding author at: Servicio de Medio Ambiente, Cabildo Insular de La Palma, Avenida Los Indianos 20, 2, 38700 Santa Cruz de La Palma, Canary Islands, Spain.

E-mail addresses: fmmhijazo@gmail.com, felix.medina@cablapalma.es (F.M. Medina).
}

Cats, brought by people, have dispersed worldwide including to many remote islands, where populations have become feral (Fitzgerald \& Turner, 2000). Once introduced, cats mainly preyed upon other introduced mammals but also native mammals, birds, reptiles and insects (Bonnaud et al., 2011), being responsible, at least in part, for $8 \%$ of global bird, mammal and reptile extinctions and the decline of almost $14 \%$ of critically endangered vertebrates on islands (Medina et al., 2011).

Predation strongly impacts upon prey population dynamics both in terms of companion (pet) cats in urban and suburban habitats (Woods, McDonald, \& Harris, 2003) and stray and feral cats in uninhabited environments (Fitzgerald \& Turner, 2000). For this reason, cats are considered as one of the 100 worst invasive species (Lowe, Browne, Boudjelas, \& De Poorter, 2000).

Faced with issues related to cat presence, eradication campaigns have been conducted on 100 islands worldwide (DIISE, 2014) using a range of techniques including trapping, hunting, poisoning, and introduction of diseases (Campbell et al., 2011; Nogales et al., 2004). Extirpation of feral cats from islands is a powerful conservation tool strongly supported by conservation organisations (Farnworth, Watson, \& Adams, 2014). Nevertheless, on inhabited islands social factors can restrict its implementation 
because the opposition of cat owners or animal rights organizations (Nogales et al., 2013; Parkes, Fisher, Robinson, \& Aguirre-Muñoz, 2014). Thus, other management strategies like trap-neuter release, trap-neuter release with removal of kittens for adoption, trap-testvaccinate-alter-return-monitor, trap-euthanize, and inaction are more often accepted (Loyd \& DeVore, 2010). Although potentially useful for small-managed groups of cats these processes maybe too expensive and not efficient enough to be applied across larger cat populations (Lohr, Cox, \& Lepczyk, 2013; Metsers, Seddon, \& van Heezik, 2010). As unowned (stray) cat numbers are positively correlated with human population density (Aguilar \& Farnworth, 2012, 2013), it is crucial to obtain analyses of social, cultural, and economic issues to increase the possibility that local communities support removal management (Proulx, 1988; Oppel, Beaven, Bolton, Vickery, \& Bodey, 2011). Cat populations can therefore be seen as an anthropogenic problem requiring community-based solutions.

Questionnaires are suitable tools to obtain public or stakeholder perceptions regarding human impacts on ecosystems, ecological management processes as well as animal management, invasive mammal impacts and human-wildlife conflicts (Farnworth et al., 2014; White, Vaughan Jennings, Renwick, \& Barker, 2005). Some of them were used to measure human attitudes toward cats specifically (Turner, 2000) and focused on different aspects like cathuman relationships (Franklin, 2007), interdependence (Haspel \& Calhoon, 1990), management options (Farnworth, Campbell, \& Adams, 2011), or predation rates (Tschanz, Hegglin, Gloor, \& Bontadina, 2011).

In the Canary Islands owners release kittens into the wild increasing feral cat populations and generating a major issue for the conservation of endangered species (Medina \& Nogales, 2009). Consequently, several control programs were conducted to regulate cat population dynamics and minimize its subsequent impact on native wildlife. To avoid undesirable conflicts between animal right organisations and conservation biologists, effective information and education campaigns were considered as a basic tool (Medina \& Nogales, 2009; Rando, 2004). Despite this, few questionnaires had been carried out on islands taking into account human attitudes and social perceptions as they relate to the presence and effects of cats on island ecologies. There have been no such studies on most of the $5 \%$ of the world's 179,000 small and medium sized islands where cats have been introduced (B. R. Tershy, personal communication) including the Canaries. The main objective of this contribution is to establish, through a questionnaire, the opinion of specific groups of La Palma Island Biosphere Reserve inhabitants toward the effect of cat presence on island ecosystems. Specifically, we aim to evaluate the following: (1) the inhabitant's knowledge about island biodiversity and the consequences of invasive species; (2) the inhabitant's opinion about cat presence; and, (3) their attitude towards cat population management. Each of these is considered in light of the respondents' specific interest group those being: local residents, environmental workers, tourists, and hunters.

\section{Material and methods}

\subsection{Study area}

The Canarian archipelago is located in the Atlantic Ocean, some $100 \mathrm{~km}$ off the African continent. With an area of $728 \mathrm{~km}^{2}$ and an altitude of $2426 \mathrm{~m}$ a.s.l. (Roque de Los Muchachos), the island of La Palma $\left(28^{\circ} 40^{\prime} \mathrm{N}, 17^{\circ} 50^{\prime} \mathrm{E}\right)$ is located in the north-west of the archipelago. Island's climate is influenced by the ecological zones associated with its altitude, the wet north-east trade winds, and the mountain orientation given a highly differentiated vegetation belts (see del Arco, Acebes, Pérez de Paz, \& Marrero, 1999 for details).

A relative small area (511 ha) on the island was declared a Biosphere Reserve in 1983 (El Canal y Los Tiles). Nevertheless, considering both the natural value of this island and the fact that only conservation programs were carried out during a long period, the entire island was declared as Biosphere Reserve in 2002, to comply with the other two functions of these natural spaces: development and logistic (support for experimentation, research, formation, education and communication). Biosphere Reserves are recognised areas of representative environments which have been internationally designated within the framework of UNESCO's Man and Biosphere Program for their value to conservation through providing the scientific knowledge, skills and values to support sustainable development (Bridgewater \& Cresswell, 1998).

\subsection{Questionnaires}

Based on Farnworth et al. (2014) study and on the focal species of our research (cats), four groups of respondents were sampled, using a written questionnaire. Such sampling design was adopted based on the assumption that points-of-view with respect to invasive predators (cats) and ecosystem conservation on the island would differ amongst groups of users. As per the aims of this work, exploring this dynamic is crucial to understanding conflicts which may arise. Groups included were: local residents (to provide a non-specialist perspective on the issues in the research); hunters (because they may treat cats as competitors for game species); environmental workers (who likely have a close relationship with nature conservation on the island); and, tourists (as non-specialists and non-locals). Questionnaires to local residents and tourists were freely available in public spaces while hunters and environmental workers were contacted at their respective associations or places to work. Adults from both sexes were able to respond. However, it is to be noted that more than $95 \%$ of the environmental workers and hunters in La Palma Island are known to be men, with a substantial bias towards older individuals. For this reason, sex and age biases were integral to the purposive sampling process and so were considered only in terms of their limitations for the study.

Between March and July 2012, 400 self-administered questionnaires were distributed amongst the principal villages proportional to the number of inhabitants. Direct and discrete questionnaires allowed avoidance of unintended influence by interviewers (Ash \& Adams, 2003).

Questions were divided in three different sections those: (1) concerned with general aspects of biodiversity on La Palma Island Biosphere Reserve, to measure the general knowledge of people about island biodiversity and the related main conservation concerns; (2) addressing specific issues about feral cats and their perceived effects on the conservation of native species; and, (3) assessing attitudes towards issues associated with the presence of cats on the island. The questionnaire (Table 1) was distributed in Spanish, English, French and German according to the respondent encountered.

\subsection{Analysis}

Survey data were analysed taking into account all the answered questionnaires and using chi-square and likelihood ratio tests (Gtest), which were commonly used in similar studies (Ash \& Adams, 2003; Haspel \& Calhoon, 1990). To answer specific questions we sub-sampled our data and when it was necessary to use the same data set and to avoid Type I error, we applied the more conservative sequential Bonferroni correction (0.05/k) proposed by Rice (1989). 


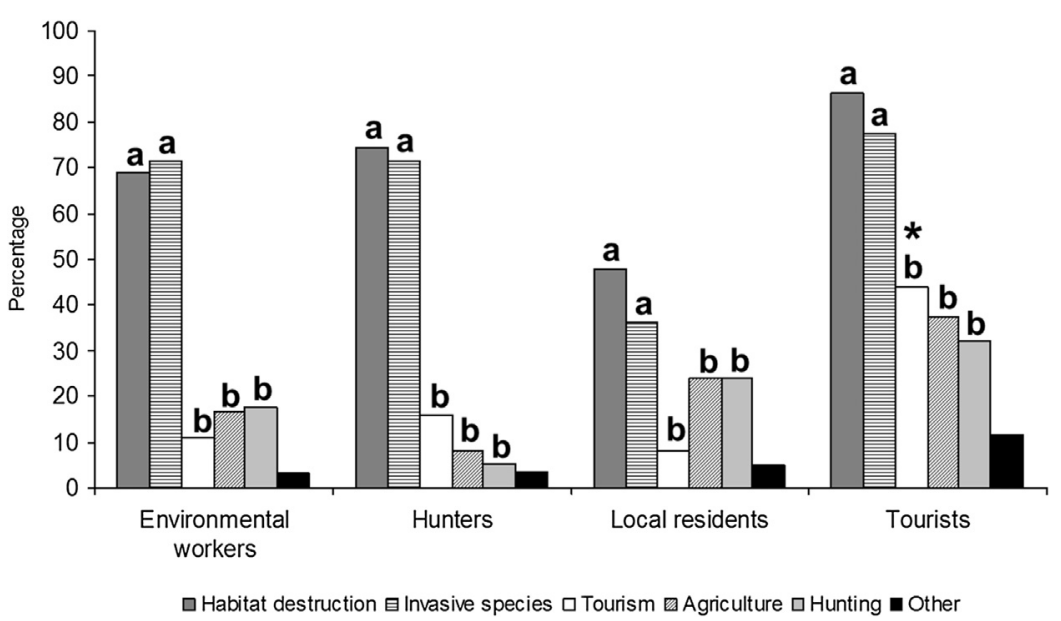

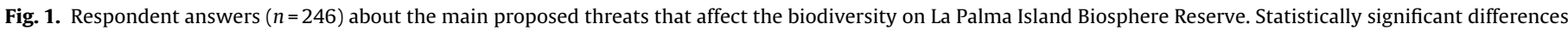

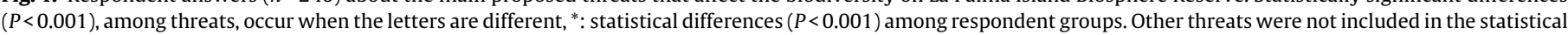
analysis.

Table 1

Applied questionnaire to know the attitude of La Palma Island Biosphere Reserve inhabitants about the island biodiversity and its conservation.

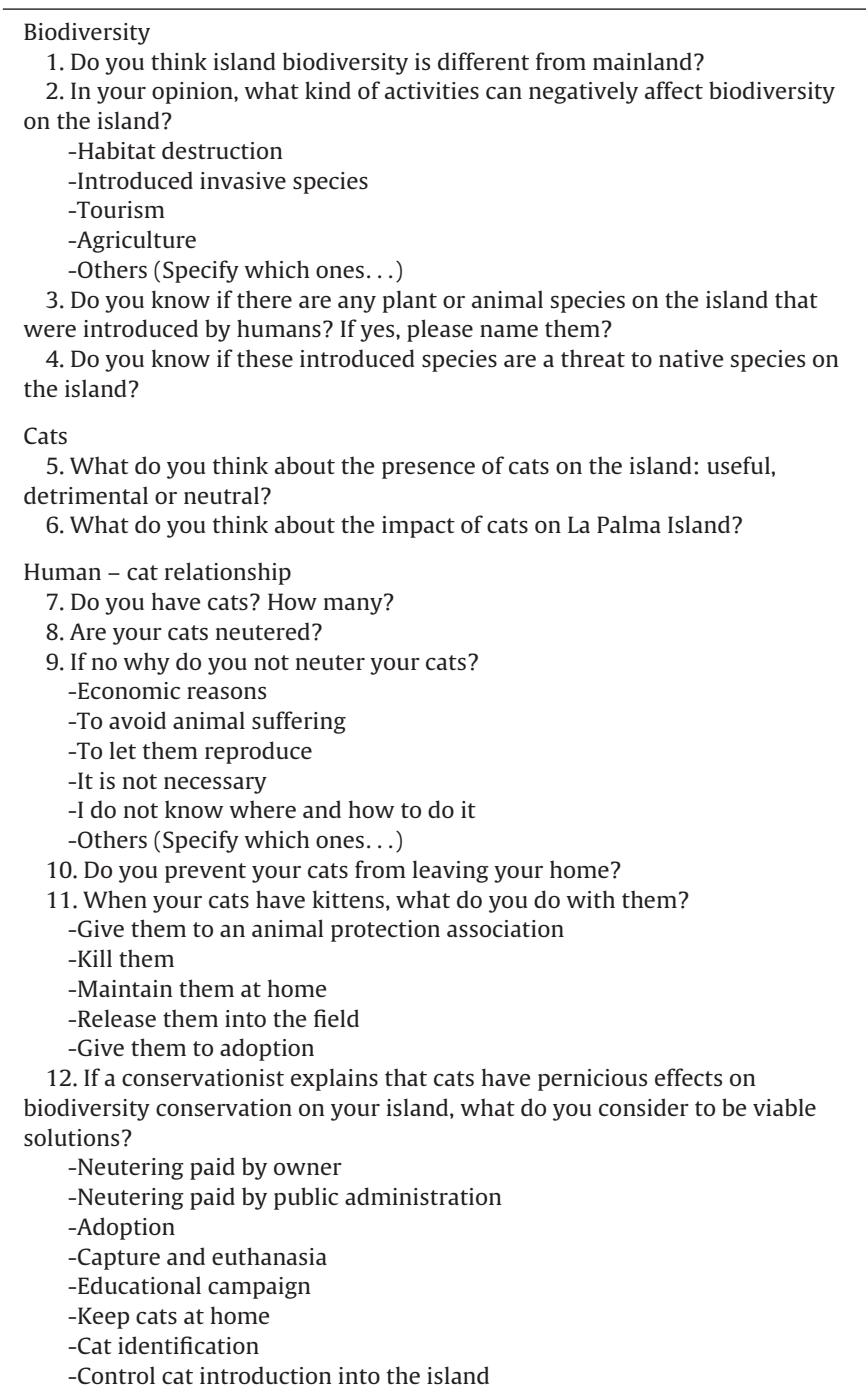

\section{Results}

386 of the 400 distributed questionnaires were successfully answered and returned. From these, 320 questionnaires were randomly considered in order to have the same sample size $(n=80)$ in each of the four social selected groups.

There was no statistically significant difference amongst groups with regard to understanding that island and mainland biodiversity differed $(G=7.67, \mathrm{df}=3, P=0.053)$. Habitat destruction and introduction of invasive species were considered the main threats for the conservation of island biodiversity $\left(\chi^{2}=405.71, \mathrm{df}=5\right.$, $P<0.001$ ) (Fig. 1). Hunters mainly did not consider hunting as a problem for biodiversity but statistical differences were not observed $\left(\chi^{2}=11.84, \mathrm{df}=3, P=0.008\right.$, Bonferroni correction $)$. Other mentioned threats included contamination, climate change and incorrect use of poisons. Of the tourists interviewed, $44 \%$ thought that tourism was one of the main threats to conservation of the island $\left(\chi^{2}=41.35, \mathrm{df}=3, P<0.001\right)$ (Fig. 1 ).

Of the respondents, $73.9 \%$ knew that invasive species are present on the island. Tourists showed the lowest knowledge (41\%) about this issue $\left(\chi^{2}=64.02, \mathrm{df}=3, P<0.001\right.$ ). Ten species (seven animals and three plants) were cited in $73.7 \%$ of the total answers (Appendix A). Among animals, barbary sheeps (Ammontragus lervia), rabbits (Oryctolagus cuniculus), rats (Rattus rattus), mice (Mus musculus domesticus) and cats were the most mentioned, while crimson fountaingrass (Pennisetum setaceum) was the most cited plant species. Most respondents $(77 \%, n=182)$ considered these invasive species to be a substantial problem for the conservation of native biodiversity. However, this concern changes significantly between groups $(G=30.35, \mathrm{df}=3, P<0.001)$, more hunters thought that invasive species are not a substantial threat. Of 307 questionnaires, 141 respondents (45.9\%) considered competition with native species as the main impact.

Most respondents answered that the presence of cats on the island had a negative effect on its biodiversity $(n=129)$. This effect was considered neutral by tourists and local residents and detrimental by hunters; no statistical differences appeared amongst groups ( $\chi^{2}=16.39, \mathrm{df}=6, P=0.012$, Bonferroni correction). The main cat negative effects mentioned by 127 specific answers were impacts on native species $(n=54)$ and diseases spread $(n=6)$. Contrarily, the main positive effect mentioned was their predation of rodents $(n=15)$.

Nearly all respondents (97.8\%, $n=313$ of 320 questionnaires) had cats at home (Fig. 2). All interviewed tourists answered that 


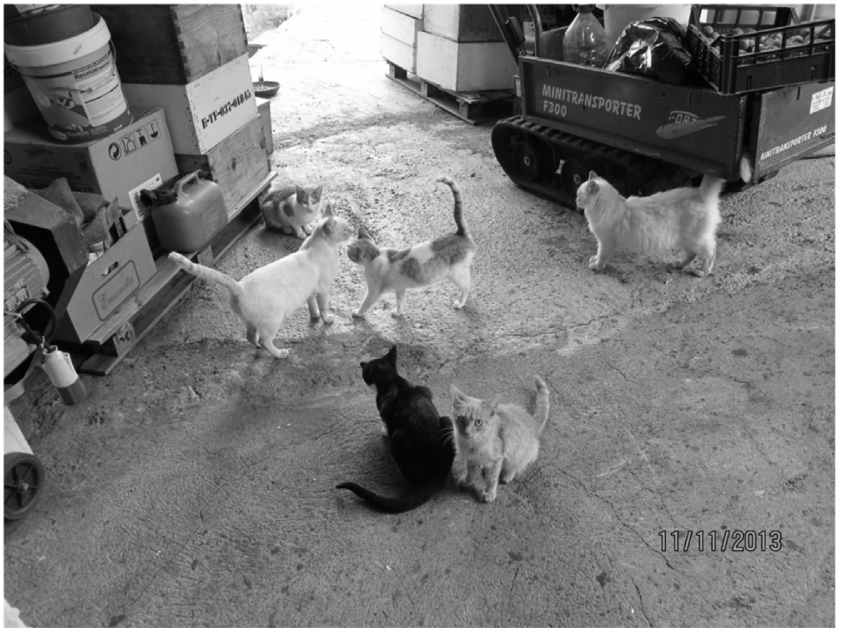

Fig. 2. Farm cats in a locality of La Palma Island Biosphere Reserve.

they did not bring their cats with them. For this reason this group was not taken into account in the following questions (8-11, see Table 1 ). Main owners (85.7\%) have $1-5$ cats at home, while some of them (7.1\%) maintained $6-20$ cats; $2.9 \%$ of respondents have more than 20 cats and $4.3 \%$ of the respondents do not know how many cats they actually have at home. $58 \%$ of respondents, among cat owners, did not neuter their cats. No statistical difference was observed amongst respondent groups $\left(\chi^{2}=1.46, \mathrm{df}=2, P=0.483\right)$. The main reason was that respondents did not think it useful (46\%) $(G=21.12, \mathrm{df}=5, P=0.001)$. However, only economic reasons and not knowing where and when it can be done were also mentioned. No other reasons were specifically mentioned.

More than $70 \%$ of respondent cat owners said that their cats have free access to natural habitats. On the other hand, most of them $(n=115)$ answered that when their cats bred, they gave the kittens up for adoption $(G=95.5, \mathrm{df}=8, P<0.001)$. Only in $4 \%$ of the cases (all of them local residents) an animal protection association was cited as a solution, while $36 \%$ of the owners maintain kittens at home as pets and 18\% decided to kill them at birth (Fig. 3). Lastly, 7\% of the respondent cat owners released kittens into the environment ( $16.7 \%$ of hunters took this decision).

Several alternative management options were proposed to respondents (Table 1). Cat sterilization paid for by the owners was considered the best option by $42 \%$ of respondents (including tourists in this last question) and $40.6 \%$ considered education campaigns necessary (Fig. 4). The solution was different dependent upon the respondent groups $\left(\chi^{2}=133.71, \mathrm{df}=24, P<0.001\right)$. Education programs were the most accepted solution for environmental workers and local residents, while capture and euthanasia was the most accepted by hunters (55.3\%). Sterilisation paid for by cat owners was mainly mentioned by tourists possibly representing an assumed cultural norm that was misaligned with that of their destination.

\section{Discussion}

This questionnaire was a useful tool to better understand the attitudes of people towards cats and cat impacts upon wildlife as well as their considerations regarding appropriate control methods for cat populations (White et al., 2005). The 320 analysed responses represented $0.35 \%$ of the total island population (ca. 87,000 inhabitants plus 23,000 tourists visiting the island during the survey). This percentage, as well as the $95.5 \%$ of response rate, is in accordance with the recommended values for robust in-person interviews (White et al., 2005).
In general respondents were aware of the peculiarity of island biodiversity and the threats of invasive species (and specifically cats) for native wildlife. Beyond their value as companion animals, cats were considered useful for the control of rodents (Haspel \& Calhoon, 1990). Respondents also used cats to control native insects, lizards, and birds because they are considered to damage crops.

As for other islands (e.g. New Zealand: Farnworth, Campbell, \& Adams, 2010) cat management is not legislatively enforced and most cat owner respondents do not control their pet movements beyond their property. On this island, urban and natural areas are often adjacent and cats can easily move between them, covering long distances and increasing their negative effect on wildlife. Unlike the Farnworth, Campbell et al. (2010) study in New Zealand most of the inhabitants of La Palma had not sterilized their cats, so companion cats wandering increases both (i) the reproductive dynamics of feral populations and (ii) the predation pressure upon native species (Medina \& Nogales, 2009). Plus, inhabitants have a lot of cats at home and they release kittens into natural habitats after their pets breed (Medina \& Nogales, 2009). During the survey (five months) at least 11 cats were known to be released in urban and natural areas. Active abandonment of reproductively viable cats requires substantial investigation. This is especially so considering that undesirable owner behaviours (such as abandonment) sustain feral cat populations (Finkler \& Terkel, 2012) which, in turn, may pose a risk to protected species (Aguilar, Farnworth, \& Winder, 2015).

Respondents commented that neutering their cats is not of primary importance and above all they are not aware of this surgical procedure and its cost. Consequently, it appeared (1) a lack of information about sterilization processes considered expensive, complicated and dangerous for cats and (2) a need for education about cat impact on native fauna and natural island ecosystems in general. One solution could be to subsidize sterilizations (Oppel et al., 2014), and convince owners to keep their cats inside their property (Lepczyk et al., 2010). Some authors argue that the more owners care about their cats (i.e. resource, social and health needs) the less impact cats have on prey populations (Kays \& DeWan, 2004). However, the harmful effects of free-ranging companion cats upon native species are still substantial, especially when cat population density is high (e.g. Medina et al., 2011).

Differences observed between the four group's answers could represent cultural differences and divergent points of view towards nature and ecosystem preservation. However, it is also important to note that the groups also contained inherent biases, for example hunters and conservation workers sample were almost entirely male biased samples. It is not possible to extricate such biases from the purposively sampled data and the conclusions drawn should be considered in light of this. The most significant difference observed was that hunters, as opposed to other groups, did not consider invasive species a substantial threat to biodiversity conservation efforts. This is likely because two of the most pernicious invasive mammals on the island, the rabbit and the barbary sheep, are the most important game animals for them. Furthermore, it was surprising that although hunters reported cats as highly detrimental and requiring lethal control to minimise competition for game, they were the respondent group that most commonly released kittens into the environment. The lack of awareness about conservational requirements within the biosphere is probably due to a lack of enough informative campaigns about the risks of invasive species, particularly cats. As expected, environmental workers showed more specific knowledge as they have received specific education regarding this issue. Lastly, as far as we know, no informative campaigns are presented to the tourists before they visit the island. Such contradictions between tourist expectations and local practices may impact negatively on tourists' perceptions of their visit, especially 


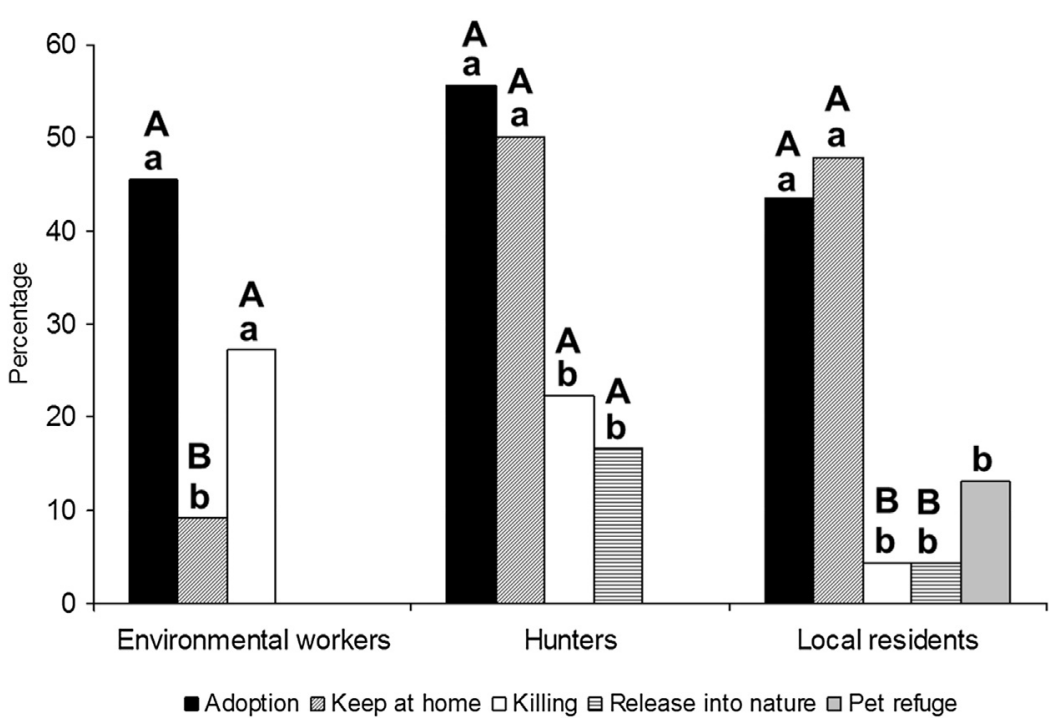

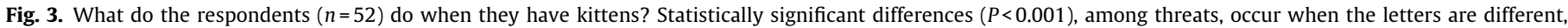
Capital letters: statistical differences $(P<0.001)$ among respondent groups.

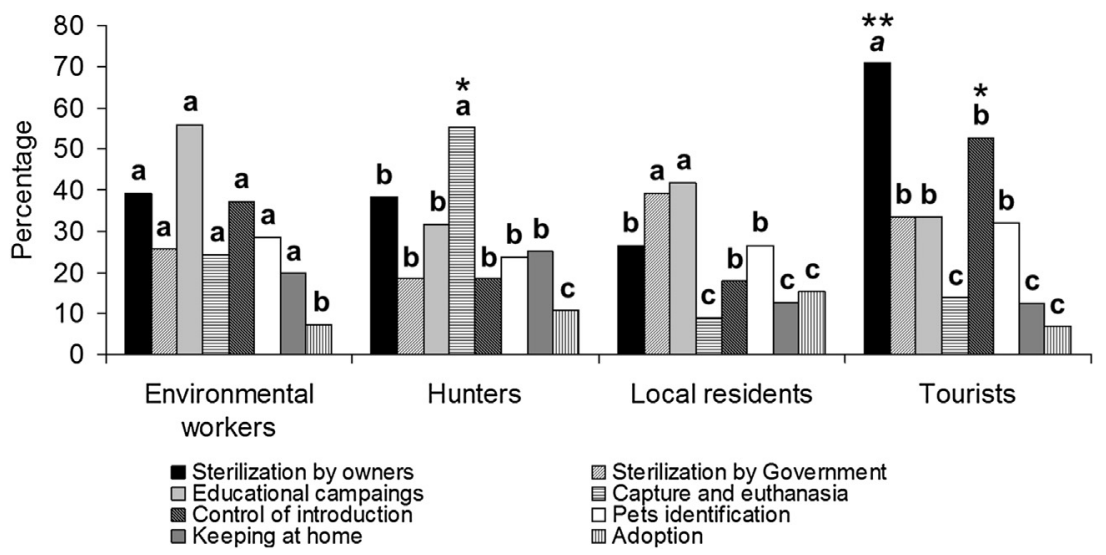

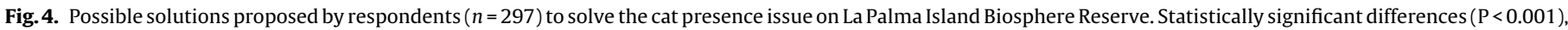
among solutions, occur when the letters are different, ${ }^{*}$ : statistical differences $(P<0.001)$ among respondent groups, ${ }^{* *}$ and italics: $P<0.05$.

if differences are considered to be at the expense of animal welfare (Beckman et al., 2014). We consider that educational campaigns are likely to be the most effective tools for improving social knowledge about the negative effects of feral organisms and their management (40.6\% of respondents in this study; e.g. Loyd \& DeVore, 2010).

In general trap-euthanize is considered the most efficient management tool to control for feral cat population (Loyd \& DeVore, 2010). On La Palma Biosphere Reserve, several sterilization campaigns have been conducted by animal rights associations, with the collaboration of the Island Government (Cabildo de La Palma) without specific objectives. Considering the current impacts of cats (Medina, García, \& Nogales, 2006), and the results of this questionnaire, the most valuable management action on this island may be to conduct massive owned-cat sterilization campaigns, as well as capture and euthanize feral and stray cats in priority areas for conservation. This could be the best solution for avoiding welfare compromise of cats impossible to adopt (Lepczyk et al., 2010). Although this management action may not be efficient enough to mitigate all issues (Oppel et al., 2011), it is one of the best solutions when total eradication is undesirable or impossible (Farnworth et al., 2011). Similar management decisions have already been applied worldwide to: (1) obtain a compromise between Governments, stakeholders, and pet owners; (2) reduce or prevent abandonment of kittens into the environment; and, (3) decrease the number of domestic cats in urban and suburban areas (Hervías et al., 2012).

\section{Conclusions}

Cats are currently affecting at least 13 Critically Endangered species on 12 islands worldwide. On such islands eradication has been considered as a priority for native wildlife conservation, and effective education or social programs are required for increasing the awareness of local communities to conservation problems (Nogales et al., 2013). European laws establish that domestic animals must be kept under owner control and their release into nature is forbidden. Without any political emphasis a continuous increase in the feral cat population seems inevitable. As cat control techniques may be unpopular, educational and awareness campaigns are required to increase public understanding and acceptance (Proulx, 1988). Underlying the divergent status and respective impact of neutered domestic, stray and feral cats can improve cat control acceptance (Farnworth et al., 2011). Cat population management is a multi-factorial problem which requires engagement with numerous stakeholder groups. This may prove problematic as such groups, as shown here, may fundamentally dif- 
fer in their approach to, and consideration of, the issues involved. It is therefore important to promote an adaptive decision-making process which engages all stakeholders (Perry \& Perry, 2008; van Heezik, 2010). Only by focussing on areas of consensus can the conflicts which arise between domestic cats, protected species and their respective human caretakers be solved.

\section{Acknowledgements}

We are grateful to all the respondents on La Palma Island Biosphere Reserve, as well as all the people who helped us when conducting this questionnaire. Marcela Niño helped us with the social aspects of questionnaires and translated them into English making interesting comments to preliminary results. Katarina Smith translated questionnaires into German and helped us in the field. Francisco Sánchez, José Javier Fernández, Narciso Lorenzo, and Rafael Pedro Rodríguez from the Servicio de Medio Ambiente del Cabildo Insular de La Palma for their logistic support. Steffen Oppel made useful comments on the first draft of this manuscript.

\section{Appendix A.}

List of the main invasive exotic species mentioned by respondents and number of time citing regarding question number 3: Do you know if there are any plant or animal species on the island that were introduced by humans? If yes, please name them?

\begin{tabular}{|c|c|c|}
\hline Species & Taxonomic group & Number \\
\hline Crimson fountaingrass (Pennisetum setaceum) & Plant & 53 \\
\hline Barbary sheep (Ammotragus lervia) & Mammal & 37 \\
\hline Feral cat (Felis silvestris catus) & Mammal & 28 \\
\hline Rodents (Rattus spp - Mus musculus) & Mammal & 25 \\
\hline Rabbits (Oryctolagus cuniculus) & Mammal & 23 \\
\hline Rose-ringed parakeet (Psittacula krameri) & Bird & 17 \\
\hline Snakesroots (Ageratina adenophora and A. riparia) & Plant & 8 \\
\hline Snakes (Or. Squamata) & Reptile & 7 \\
\hline Sweet chestnut (Castanea sativa) & Plant & 5 \\
\hline Dog (Canis familiaris) & Mammal & 5 \\
\hline Banana (Musa acuminata) & Plant & 5 \\
\hline Goat (Capra hircus) & Mammal & 4 \\
\hline Insects (Hexapoda) & Invertebrate & 4 \\
\hline Green iguana (Iguana iguana) & Reptile & 3 \\
\hline Ferret (Mustela furo) & Mammal & 3 \\
\hline Barbary partridge (Alectoris barbara) & Bird & 3 \\
\hline Domestic pigeon (Columba livia) & Bird & 3 \\
\hline Monterey pine (Pinus radiata) & Plant & 3 \\
\hline Barbary falcon (Falco pelegrinoides) & Bird & 2 \\
\hline Tomatoes (Solanum lycopersicum) & Plant & 2 \\
\hline Potatoes (Solanum tuberosum) & Plant & 2 \\
\hline Avocado (Persea americana) & Plant & 2 \\
\hline Eucalypt (Eucalyptus spp.) & Plant & 2 \\
\hline Sugarcane (Saccharum officinarum) & Plant & 2 \\
\hline Tobbaco (Nicotiana tabacum) & Plant & 2 \\
\hline Common walnut (Juglans regia) & Plant & 2 \\
\hline Common fig (Ficus carica) & Plant & 2 \\
\hline Bay laurel (Laurus nobilis) & Plant & 2 \\
\hline Maize (Zea mays) & Plant & 1 \\
\hline Bees (Apis melifera) & Invertebrate & 1 \\
\hline European seabass (Dicentrarchus labrax) & Fish & 1 \\
\hline Horse (Equus ferus caballus) & Mammal & 1 \\
\hline Hottentotfig (Carpobrotus edulis) & Plant & 1 \\
\hline Dromedary (Camelus dromedarius) & Mammal & 1 \\
\hline Cactus (Fam. Cactaceae) & Plant & 1 \\
\hline Crocodile (Crocodylus niloticus) & Reptile & 1 \\
\hline Acacia (Acacia spp.) & Plant & 1 \\
\hline California poppy (Eschscholzia californica) & Plant & 1 \\
\hline Veiled chameleon (Chamaeleo calyptratus) & Reptile & 1 \\
\hline Guinea pig (Cavia porcellus) & Mammal & 1 \\
\hline African collared dove (Streptopelia roseogrisea) & Bird & 1 \\
\hline Papaya (Carica papaya) & Plant & 1 \\
\hline Camelus (Camelus bactrianus) & Mammal & 1 \\
\hline
\end{tabular}

Almond (Prunus dulcis) Mango (Mangifera indica) Cockroaches (Or. Blattodea)

Barbary ground squirrel (Atlantoxerus getulus)

Pond sliders (Trachemys scripta)

Sheep (Ovis aries)

$\begin{array}{ll}\text { Plant } & 1 \\ \text { Plant } & 1 \\ \text { Invertebrate } & 1 \\ \text { Mammal } & 1 \\ \text { Reptile } & 1 \\ \text { Mammal } & 1\end{array}$

\section{References}

Aguilar, G. D., \& Farnworth, M. J. (2012). Stray cats in Auckland, New Zealand: Discovering geographic information for exploratory spatial analysis. Applied Geography, 34, 230-238

Aguilar, G. D., \& Farnworth, M. J. (2013). Distribution characteristics of unmanaged cat colonies over a 20 year period in Auckland, New Zealand. Applied Geography, 37, 160-167.

Aguilar, G. D., Farnworth, M. J., \& Winder, L. (2015). Mapping the stray domestic cat (Felis catus) population in New Zealand: Species distribution modelling with a climate change scenario and implications for protected areas. Applied Geography, 63, 146-154

Ash, S. J., \& Adams, C. E. (2003). Public preferences for free-ranging domestic cat (Felis catus) management options. Wildlife Society Bulletin, 31, 334-339.

Beckman, M., Hill, K. E., Farnworth, M. J., Bolwell, C. F., Bridges, J., \& Acke, E. (2014). Touristsí perceptions of the free-roaming dog population in Samoa. Animals, 4 , 599-611.

Bonnaud, E., Medina, F. M., Vidal, E., Nogales, M., Tershy, B., Zavaleta, E., et al. (2011). The diet of feral cats on islands: A review and a call for more studies. Biological Invasions, 13, 581-603.

Bridgewater, P. B., \& Cresswell, I. D. (1998). The reality of the world network of biosphere reserves: Its relevance for the implementation of the convention on biological diversity. In Proceedings of a workshop at the 1996 IUCN world conservation congress, biosphere reserves -myth or reality? (pp. 1-6)

Campbell, K. J., Harper, G., Algar, D., Hanson, C. C., Keitt, B. S., \& Robinson, S. (2011). Review of feral cat eradications on islands. In C. R. Veitch, M. N. Clout, \& D. R. Towns (Eds.), Island invasives: eradication and management. proceedings of the international conference on island invasives (pp. 37-46).

del Arco, M., Acebes, J. R., Pérez de Paz, P. L., \& Marrero, M. C. (1999). Bioclimatology and climatophilus vegetation of hierro (part 2) and La Palma (Canary islands). Phytocoenologia, 29, 253-290.

DIISE. (2014). Database of island invasive species eradications. Island conservation.. Available from http://diise.islandconservation.org (accessed 30.12.14.).

Driscoll, C. A., Menotti-Raymond, M., Roca, A. L., Hupe, K., Johnson, W. E., Geffen, E., et al. (2007). The near eastern origin of cat domestication. Science, 317 519-523.

Farnworth, M. J., Dye, N. G., \& Keown, N. (2010). The legal status of cats in New Zealand: A perspective on the welfare of companion, stray and feral domestic cats (Felis catus). Journal of Applied Animal Welfare Science, 13, 180-188.

Farnworth, M. J., Campbell, J., \& Adams, N. J. (2010). Public awareness in New Zealand of animal welfare legislation relating to cats. New Zealand Veterinary Journal, 58, 213-217.

Farnworth, M. J., Campbell, J., \& Adams, N. J. (2011). What's in a name? Perceptions of stray and feral cat welfare and control in Aotearoa, New Zealand. Journal of Applied Animal Welfare Science, 14, 59-74.

Farnworth, M. J., Watson, H., \& Adams, N. J. (2014). Understanding control of non-native wild and feral mammals: Similarities and differences in the opinions of the general public, animal protectionists and conservationists in New Zealand (Aotearoa). Journal of Applied Animal Welfare Science, 17, 1-17.

Finkler, H., \& Terkel, J. (2012). The contribution of owners' attitudes and behaviours to the free-roaming cat overpopulation in Tel Aviv, Israel. Preventive Veterinary Medicine, 104, 125-135.

Fitzgerald, B. M., \& Turner, D. C. (2000). Hunting behaviour of domestic cats and their impact on prey populations. In D. C. Turner, \& P. Bateson (Eds.), The domestic cat: the biology of its behaviour (2nd ed., pp. 152-175). Cambridge, UK: Cambridge University Press.

Franklin, A. (2007). Human-nonhuman animal relationships in Australia: An overview of results from the first national survey and follow-up case studies 2000-2004. Society and Animals, 15, 7-27.

Haspel, C., \& Calhoon, R. E. (1990). The interdependence of humans and free-ranging cats in Brooklyn, New York. Anthrozoös, 3, 155-161.

Hervías, S., Silva, C., Pipa, T., Oliveira, N., Henriques, A., Geraldes, P. L., et al. (2012). Invasive mammal species on Corvo Island: Is their eradication technically feasible. Airo, 22, $12-28$

Kays, R. W., \& DeWan, A. A. (2004). Ecological impact of inside/outside house cats around a suburban nature preserve. Animal Conservation, 7, 273-283.

Lepczyk, C. A., Dauphiné, N., Bird, D. M., Conant, S., Cooper, R. J., Duffy, D. C., et al. (2010). What conservation biologists can do to counter trap-neuter-return: Response to Longcore et al. Conservation Biology, 24, 627-629.

Liberg, O., Sandell, M., Pontier, D., \& Natoli, E. (2000). Density, spatial organisation and reproductive tactics in the domestic cat and other felids. In D. C. Turner, \& P. Bateson (Eds.), The domestic cat: the biology of its behaviour (2nd ed., pp. 119-148). Cambridge, UK: Cambridge University Press.

Lohr, C. A., Cox, L. J., \& Lepczyk, C. A. (2013). Costs and benefits of trap-neuter-release and euthanasia for removal of urban cats in Oahu, Hawaii. Conservation Biology, 27, 64-73. 
Lowe, S., Browne, M., Boudjelas, S., \& De Poorter, M. (2000). 100 of the world's worst invasive alien species: A selection from the global invasive species database. Auckland, New Zealand: The Invasive Species Specialist Group (ISSG), Species Survival Commission (SSC), World Conservation Union (IUCN).

Loyd, D. T., \& DeVore, J. L. (2010). An evaluation of feral cat management options using a decision analysis network. Ecology and Society, 15(10). Available from http://www.ecologyandsociety.org/vol15/iss4/art10/ (accessed 21.10.13.).

Medina, F. M., \& Nogales, M. (2009). A review of the impacts of feral cats (Felis silvestris catus) in the Canary Islands: Implications for the conservation of its endangered fauna. Biodiversity and Conservation, 18, 829-846.

Medina, F. M., García, R., \& Nogales, M. (2006). Feeding ecology of feral cats on a subtropical heterogeneous oceanic island (La Palma, Canarian Archipelago). Acta Theriologica, 51, 75-83.

Medina, F. M., Bonnaud, E., Vidal, E., Tershy, B. R., Zavaleta, E. S., Donlan, C. J., et al (2011). A global review of the impacts of invasive cats on island endangered vertebrates. Global Change Biology, 17, 3503-3510.

Metsers, E. M., Seddon, P. J., \& van Heezik, Y. M. (2010). Cat-exclusion zones in rural and urban-fringe landscapes: How large would they have to be? Wildlife Research, 37, 47-56

Nogales, M., Martín, A., Tershy, B. R., Donlan, C. J., Veitch, D., Puerta, N., et al. (2004). A review of feral cat eradication on islands. Conservation Biology, 18, 310-319.

Nogales, M., Vidal, E., Medina, F. M., Bonnaud, E., Tershy, B. R., Campbell, K. J., et al. (2013). Feral cats and biodiversity conservation: The urgent prioritization of island management. Bioscience, 63, 804-810.

Oppel, S., Beaven, B. M., Bolton, M., Vickery, J., \& Bodey, T. W. (2011). Eradication of invasive mammals on islands inhabited by humans and domestic animals. Conservaton Biology, 25, 232-240.
Oppel, S., Burns, F., Vickery, J., George, K., Ellick, G., Leo, D., et al. (2014). Habitat-specific effectiveness of feral cat control for the conservation of an endemic ground-nesting bird species. Journal of Applied Ecology, 51, 1246-1254.

Parkes, J., Fisher, P., Robinson, S., \& Aguirre-Muñoz, A. (2014). Eradication of feral cats from large islands: An assessment of the effort required for success. New Zealand Journal of Ecology, 38, 307-314.

Perry, D., \& Perry, G. (2008). Improving interactions between animal rights groups and conservation biologists. Conservation Biology, 22, 27-35.

Proulx, G. (1988). Control of urban wildlife predation by cats through public education. Environmental Conservation, 15, 358-359.

Rando, J. C. (2004). Aspectos legales relacionados con el control de gatos vagabundos. La Laguna University. Unpublished study.

Rice, W. R. (1989). Analyzing tables of statistical tests. Evolution, 43, 223-225.

Tschanz, B., Hegglin, D., Gloor, S., \& Bontadina, F. (2011). Hunters and non-hunters: Skewed predation rate by domestic cats in a rural village. European Journal of Wildlife Research, 57, 597-602.

Turner, D. C. (2000). The human-cat relationship. In D. C. Turner, \& P. Bateson (Eds.), The domestic cat: the biology of its behaviour (2nd ed., pp. 193-206). Cambridge: Cambridge University Press.

van Heezik, Y. (2010). Pussyfooting around the issue of cat predation in urban areas. Oryx, 44, 153-154.

White, P. C. L., Vaughan Jennings, N., Renwick, A. R., \& Barker, N. H. L. (2005). Questionnaires in ecology: A review of past use and recommendations for best practice. Journal of Ecology, 42, 421-430.

Woods, M., McDonald, R. A., \& Harris, S. (2003). Predation of wildlife by domestic cats Felis catus in Great Britain. Mammal Review, 33, 174-188. 